\title{
Segurança no trabalho e desenvolvimento de produto: diretrizes para integração na construção civil
}

\author{
Tarcisio Abreu Saurin, Dr. \\ Universidade Federal do Rio Grande do Sul (UFRGS)
}

\begin{abstract}
Resumo
Este trabalho apresenta diretrizes para a integração de requisitos de segurança no trabalho à etapa de desenvolvimento de produto (DP) na construção civil. As diretrizes foram desenvolvidas a partir de entrevistas com um grupo de sete projetistas da construção civil, uma entrevista com a projetista de ar condicionado e um estudo exploratório de integração da segurança ao processo de DP. Embora as entrevistas tenham indicado que a integração ainda é uma prática pouco disseminada na construção, a preocupação com a segurança do usuário final, assim como a boa receptividade a uma futura lei que obrigue a integração da segurança aos projetos lcomo já existe na União Européia), são indícios da viabilidade da mudança desta realidade. Em termos operacionais, propõe-se que a integração esteja fundamentada na adoção do ciclo de gerenciamento de riscos em cada etapa do projeto, assim como em bancos de dados de medidas práticas de integração adequadas à realidade nacional. Além disso, há amplas oportunidades para que a segurança seja considerada como mais uma dimensão nas técnicas e modelos existentes de desenvolvimento de produto.
\end{abstract}

Palavras-chave

Segurança no trabalho; desenvolvimento de produto; gerenciamento de riscos; construção civil.

\section{Safety and product development: guidelines for integration in construction}

\begin{abstract}
This paper presents guidelines for integrating safety into the product development process in construction industry. As a basis for developing the guidelines the following data were collected: interviews with seven designers from construction industry; an interview with a designer of air conditioners; an exploratory study of integration of safety into product development. Even though the interviews have pointed out that the integration is still adopted to a minor extent in construction, there were evidences that this reality might be changed. Designers both usually took into account safety of end users and were likely to welcome a regulation that established safety into design as a mandatory requirement, similarly to what occurs in the European Union. For practical purposes, it is suggested that the integration be based on the adoption of the risk management cycle throughout all stages of the product development process as well as on databases that comprise measures for safe design fitted to Brazilian reality. Also, there is plenty of room for considering safety as one further dimension in the existing techniques and models of product development.
\end{abstract}

Key words

Safety; product development; risk management; construction. 


\section{INTRODUC̣̃̃O}

No âmbito das medidas que vêm sendo estudadas para a redução de acidentes na indústria da construção, a integração dos requisitos de segurança à etapa de desenvolvimento de produto (DP) parece ser uma das alternativas com maior potencial de benefícios, uma vez que pode eliminar ou reduzir os perigos nas suas origens. A integração da segurança ao DP também é necessária pois as falhas de projeto são uma das mais importantes categorias de causa-raiz dos acidentes no setor (CHURCHER e STARR, 1997). Além disso, a discussão de assuntos de segurança desde as etapas iniciais do empreendimento implica em grande antecipação dos perigos e, conseqüentemente, mais tempo para o estudo de métodos de trabalho seguros.

Em nível internacional, a implementação prática da integração da segurança ao DP tem sido mais intensa nos países da União européia, uma vez que, de acordo com a Diretiva Européia 92/57/CEE (Prescrições Mínimas de Segurança e Saúde a Aplicar nos Canteiros Móveis e Temporários) os projetistas são obrigados a conduzir uma análise formal dos riscos de acidentes envolvidos na execução de seus projetos. De acordo com Lakka e Sauni (1999), a legislação européia tem mudado o foco da responsabilização pelos acidentes em direção aos que planejam a segurança, incluindo projetistas e proprietários. Durante a fase de elaboração de projetos, assim como na fase de construção, a Diretiva exige a existência de um coordenador de segurança e saúde, que deve ser pessoa física ou jurídica indicada pelo proprietário. Na Finlândia e na França, os proprietários freqüentemente têm apontado o arquiteto como coordenador na fase de projeto (LAKKA e SAUNI, 1999). Pressões legais também têm induzido à adoção da abordagem nos Estados Unidos. Embora naquele país não exista lei similar à Diretiva Européia, Coble e Blatter (1999) e Prugh (1996) relatam a incidência crescente de ações judiciais, especialmente contra arquitetos, movidas em função da negligência de requisitos de segurança no trabalho no DP.

As barreiras que dificultam a integração da segurança ao DP também têm sido investigadas. Por exemplo, Hinze e Gambatese (1996) atribuem duas causas principais à falta de envolvimento dos projetistas com o tema: a tentativa de evitar responsabilidades legais sobre acidentes de trabalho e o pouco conhecimento em relação a assuntos de segurança, uma vez que os cursos de graduação em engenharia e arquitetura muitas vezes sequer incluem disciplinas acerca do tema. Com base na experiência de aplicação da Diretiva Européia, Mackenzie et al. (2000) ainda acrescentam outras causas: os curtos prazos estipulados pelo cliente, de modo que os requisitos de segurança tornam-se secundários em comparação a demandas mais urgentes; a escassez de informações na etapa de projeto, especialmente nas fases iniciais.

Diversos estudos têm apresentado sugestões de medidas práticas para a consideração da segurança na etapa de projeto (HISLOP, 1999; HINZE e GAMBATESE, 1996; MACCOLLUM, 1995). Por exemplo, a Fundação Européia para a Melhoria das Condições de Vida e do Trabalho (1989) sugere o uso de painéis pré-moldados de fachadas que dispensam a colocação de guarda-corpos, uma vez que a parte superior de cada módulo da fachada já cumpre a função de guarda-corpo. Além disso, em estudo voltado à consideração da segurança nos projetos para os usuários finais, Sinnott (1985) apresenta uma série de sugestões que também são úteis para a segurança dos trabalhadores durante a execução e manutenção. Contudo, as sugestões apresentadas nesses estudos devem ser analisadas com cautela, devido a três motivos: há medidas não aplicáveis à realidade brasileira (por exemplo, projetar rampas com orientação solar que minimize o acúmulo de neve); os princípios técnicos que embasam as mesmas algumas vezes não são evidentes (por exemplo, usar no mínimo dois parafusos por conexão em estruturas metálicas); muitas sugestões são vagas e saem do escopo do projeto do produto (por exemplo, os cronogramas devem minimizar o uso de horas-extras).

De modo geral, os estudos a respeito da integração da segurança aos projetos têm enfatizado a proposição de medidas práticas para implementar a integração, semelhantes às ilustradas acima, ou relatos das experiências de aplicação da Diretiva Européia. Dentre os temas que merecem investigações mais detalhadas, pode-se destacar a inserção da segurança no processo de DP, assim como o desenvolvimento de métodos para implementar essa integração. Este trabalho pretende contribuir para o preenchimento destas lacunas ao apresentar diretrizes para a integração da segurança ao processo de DP na construção civil.

\section{INTEGRAC̄̃̃O DE REQUISITOS DE SEGURANC̣A AO DP EM OUTRAS INDÚSTRIAS}

$\mathrm{Na}$ literatura relativa a outras indústrias, os estudos pesquisados costumam se referir à integração de requisitos ergonômicos à etapa de DP, o que também inclui as questões de segurança no trabalho. De acordo com Budnick et al. (1996), os métodos de produção são uma preocupação para os ergonomistas, uma vez que atividades de montagem, manuseio de materiais e inspeção são importantes contribuintes para problemas de natureza ergonômica. Considerando que as características dessas atividades são em grande parte determinadas por deci- 
sões de projeto do produto, é de interesse da ergonomia estudar os efeitos desse projeto nos tipos de tarefas criadas nos postos de trabalho (HELANDER e WILLÉN, 1999).

Entretanto, é irônico que a consideração dos requisitos humanos no DP tenha ganhado impulso a partir da disseminação do uso de robôs e da consideração de seus requisitos. No começo da década de 80 , havia a percepção de que os robôs poderiam realizar apenas tarefas de montagem simples, as quais não requeressem grande precisão de movimentos e fossem fáceis de programar (HELANDER e FURTADO, 1992). Assim, tendo em vista aumentar a utilização dos robôs, foi necessário reprojetar os produtos de modo que eles fossem fáceis de montar. Nesse contexto, foi desenvolvida a técnica de reprojeto denominada Design for Assembly (DFA) (BOOTHROYD e DEWHURST, 1983), a qual propunha diretrizes para facilitar a montagem automática, porém também de grande utilidade para simplificar a montagem manual. A partir dos estudos de Boothroyd e Dewhurst (1983), diversas técnicas DFx (Design for X) têm proliferado, sendo que $X$ representa um ponto de vista particular. Dentre outras, existe o DFM (Design for Manufacturability), o DFD (Design for Disassembly) e o DFE (Design for Environment). Infelizmente, poucas dessas técnicas têm sido influenciadas por conhecimento ergonômico (BUDNICK et al., 1996).

Como contribuição para mudar essa realidade, Helander e Willén (1999) e Helander e Furtado (1992) propuseram um conjunto de princípios para a integração de fatores humanos no projeto do produto, caracterizando o Design for Human Assembly (DHA). Diversos desses princípios são de interesse para a construção civil, tais como: visibilidade das partes e ferramentas; discriminação visual das partes; minimizar o número de componentes e partes; usar partes simétricas; usar partes que sejam fáceis de agarrar e que não enrosquem; feedback visual, audível ou tátil para indicar que a tarefa foi finalizada.

Segundo Budnick et al. (1996), seria ideal que um ergonomista participasse em cada etapa do processo de DP. Contudo, esses autores listam barreiras para que isso ocorra na prática, tais como: dificuldade de apresentar o conhecimento ergonômico para não-especialistas; dificuldade de justificar a necessidade da ergonomia em termos econômicos; o pouco conhecimento que os ergonomistas geralmente possuem a respeito de práticas de projeto. Como alternativa, os projetistas deveriam receber treinamento básico em ergonomia durante sua formação acadêmica. Uma vez que isso ainda não é uma realidade, há necessidade do desenvolvimento de métodos que integrem o conhecimento ergonômico em ferra- mentas já existentes de DP. Em particular, Budnick et al. (1996) enfatizam a necessidade de organizar o conhecimento ergonômico desde metas de alto nível até informações orientadas a soluções. Por exemplo, uma meta de alto nível pode ser que o produto seja fácil de movimentar, levantar ou carregar. Em maior detalhe, pode ser definido que se um produto deve ser levantado, ele deve ser fácil de agarrar e segurar. Uma vez que a facilidade de agarrar sobreviva como meta de projeto, informação ergonômica relativa a métodos para facilitar o agarramento (como tipos de alças) deve ser fornecida, com o conseqüente detalhamento de localização, orientação e especificações dimensionais.

\section{MÉTODO DE PESQUISA}

Tendo em vista desenvolver as diretrizes de integração da segurança ao DP, essa pesquisa foi constituída por cinco etapas:

a) entrevistas com projetistas da construção civil: com o objetivo de identificar as percepções de projetistas em relação ao tema estudado, foram conduzidas sete entrevistas semi-estruturadas, sendo quatro com projetistas de estrutura (entrevistados A, B, C e D) e três com projetistas de arquitetura (E, F e G). Todos tinham mais de quinze anos de experiência profissional. A maioria $(85,7 \%)$ realiza trabalhos para clientes do setor privado $(85,7 \%)$ e atua no subsetor de obras industriais $(71,4 \%)$. Após a leitura de todos os relatos, foi identificada uma estrutura de análise representativa das percepções e que incluía assuntos relevantes ao estudo. As percepções foram agrupadas em cinco tópicos: principal critério de avaliação adotado pelos clientes; vantagens e desvantagens dos processos de DP onde os entrevistados têm atuado; experiência na consideração de requisitos de segurança nos projetos; posição sobre a eventual introdução, no Brasil, de lei que obrigue os projetistas a considerar formalmente a segurança nos projetos; barreiras para a consideração de requisitos de segurança nos projetos.

b) elaboração de check-list de medidas de segurança a serem consideradas nos projetos: tendo em vista facilitar a realização de um estudo exploratório de integração (item $c$ abaixo), assim como disponibilizar uma ferramenta aos projetistas, foi desenvolvido um check-list com medidas de segurança a serem consideradas nos projetos. As principais fontes para a elaboração do check-list foram os trabalhos de Hinze e Gambatese (1997) e Sinnott (1985), além das entrevistas discutidas no item anterior.

c) estudo exploratório de integração: o estudo foi conduzido na obra de ampliação de um edifício industrial em Montenegro (RS). A obra possuía prazo de execução de seis meses, incluindo o tempo necessário para a finaliza- 
ção do projeto arquitetônico e desenvolvimento dos projetos complementares. A construtora responsável é uma empresa de médio porte atuante no segmento de obras industriais, a qual desde 2001 vem desenvolvendo trabalhos em parceria com a UFRGS na área de gestão da segurança. $\mathrm{O}$ estudo teve as características de uma pesquisa-ação, uma vez que pesquisador e membros da empresa atuaram em colaboração para efetivar a integração das demandas de segurança aos projetos.

d) entrevista com projetista de indústria de outro setor: foi realizada uma entrevista com o coordenador de projeto de um fabricante de ar-condicionado, visando compreender como as questões de segurança eram integradas ao processo de DP. Essa empresa é uma multinacional (a planta visitada situa-se em Canoas-RS) reconhecida pela adoção de práticas sistemáticas de organização do processo de DP. Cabe salientar que a entrevista não visou o mapeamento detalhado da organização do processo de DP, mas apenas caracterizar em linhas gerais sua estrutura e identificar as estratégias de inserção das questões de segurança no mesmo.

e) proposta de diretrizes para a integração: as diretrizes foram desenvolvidas a partir dos dados levantados nas etapas anteriores da pesquisa.

\section{RESULTADOS}

\section{Entrevistas com projetistas da construção civil}

Os critérios de custo e prazo costumam ser as principais exigências dos clientes dos projetistas entrevistados, sendo que cada um obteve $38,5 \%$ do total de critérios citados. Cabe salientar que os critérios de custo e prazo, conforme descritos pelos entrevistados, se referem tanto ao custo e ao prazo da elaboração dos projetos (desenhos e memoriais) quanto ao custo e ao prazo de execução da obra, os quais são determinados em grande parte por decisões de projeto. Embora a segurança não tenha sido mencionada pelos entrevistados, nenhum dos critérios citados implica, necessariamente, em prejuízos para a mesma. Por exemplo, os critérios citados pelos entrevistados A (flexibilidade para futuras modificações) e B (soluções de interfaces entre subsistemas) têm impacto positivo na construtibilidade (facilidade de construir) e, por conseqüência, na segurança.

Algumas das características positivas e negativas dos processos de DP citadas pelos entrevistados são de interesse para o desenvolvimento de diretrizes para a integração da segurança a esses processos. Por exemplo, não parece apropriado incluir a discussão detalhada de temas de segurança durante reuniões de compatibilização de projetos, cuja pauta costuma ser extensa. Quatro dos sete entrevistados $(57,1 \%)$ reclamaram do tempo excessivo consumido por essas reuniões e do fato de que sua parti- cipação ocorria durante um período de tempo muito pequeno. Contudo, como foi salientado pelo entrevistado $\mathrm{G}$, as reuniões entre todos os projetistas são excelente oportunidade de aprendizado sobre a obra.

A importância da participação do cliente no processo de DP foi enfatizada pelo entrevistado A, sendo também esse um assunto de interesse para a integração da segurança. Embora a iniciativa para inclusão de medidas de segurança nos projetos possa partir do próprio projetista, cabe a discussão das mesmas, tão cedo quanto possível, com o cliente, tendo em vista sua aprovação. Já os entrevistados $\mathrm{C}$ e $\mathrm{D}$ mencionaram uma prática que contribui indiretamente para a identificação de perigos de acidentes: o uso de um check-list nas fases iniciais de projeto para identificar características de interesse do projeto estrutural (por exemplo, o tipo de tijolo e de reservatório de água utilizado). Nenhum dos entrevistados mencionou a elaboração de projetos para produção como prática usual de seu escritório de projetos, o que é negativo do ponto de vista da segurança.

Apenas o entrevistado $\mathrm{C}$ (projetista de pré-moldados) manifestou que leva em conta nos seus projetos, por iniciativa própria, requisitos de segurança dos trabalhadores que executam a obra. Em parte, isso é explicado pelo fato de que esse projetista pode ser considerado membro da empresa que fabrica e instala os pré-moldados, visto que ele trabalha há cerca de quinze anos quase que exclusivamente para a mesma. Logo, nesse caso, diferentemente de todos os demais entrevistados, o projetista tem estreita relação com o construtor e sofre diretamente as consequiências de decisões que impliquem em falta de segurança e construtibilidade. Contudo, o entrevistado salientou que o foco é na segurança durante a fabricação e montagem das estruturas pelo pessoal do fabricante, sendo dada pouca atenção a futuras necessidades de manutenção e ao impacto da execução dos pré-moldados na segurança de outras atividades no canteiro. De outro lado, todos os entrevistados manifestaram que procuram informalmente considerar requisitos de construtibilidade nos seus projetos.

Os entrevistados também deixaram claro que as demandas de segurança nos projetos devem partir do cliente e da construtora, em particular desta última, visto que a mesma é a principal responsável pela segurança do trabalho durante a execução. Entretanto, os relatos indicaram que raramente o cliente e a construtora fazem demandas desta natureza, havendo inércia de todas as partes para que a segurança seja de fato considerada nos projetos. É importante salientar que três entrevistados comentaram que, embora os clientes não se preocupem em atuar sobre a segurança durante a construção já nos projetos, eles se preocupam em atuar já nessa etapa sobre 
a segurança dos usuários finais, sejam moradores de um edifício ou operários de uma indústria. Por exemplo, um dos entrevistados comentou que em seu escritório é comum a realização de análises formais de riscos de incêndio quando se desenvolve o projeto elétrico. Essa prática deveria ser estendida a segurança dos usuários temporários, sendo possível que esses projetistas tenham maior facilidade de implementar a mudança, visto que as técnicas adotadas podem ser as mesmas.

Embora todos os entrevistados tenham sido capazes de citar ao menos um exemplo de risco de acidente intrínseco à execução ou manutenção das edificações por eles projetadas, nenhum deles comunica esses riscos formalmente ao construtor e ao cliente. Isso retarda o processo de identificação de riscos e, por conseqüência, seu combate na origem. Os relatos também indicaram diversas barreiras para a consideração dos requisitos de segurança nos projetos: a ausência de feedback aos projetistas acerca de problemas de falta de segurança e construtibilidade; a falta de conhecimento dos projetistas quanto a assuntos de segurança; o critério de menor preço para definir o vencedor de licitações no setor público; a falta de estimativa de custos com manutenção da edificação, o que contribui para a negligência da segurança nessas atividades; a resistência dos projetistas e clientes em aceitar sua parcela de responsabilidade na segurança dos trabalhadores; a falta da plena aplicação do código de defesa do consumidor, o que faz com que problemas de segurança durante a manutenção da edificação não sejam registrados; o relativo alto custo de algumas alternativas de projeto que melhoram a construtibilidade (por exemplo, pré-fabricação); a falta de clara identificação dos requisitos dos clientes externo e interno nos estágios iniciais do processo de DP, o que leva ao excesso de retrabalho nas soluções de projeto, sejam elas relacionadas ou não à segurança.

Os entrevistados ainda manifestaram sua opinião quanto a eventual introdução, no Brasil, de uma lei determinando que os projetistas considerem formalmente requisitos de segurança nos seus projetos, similarmente ao que já ocorre nos países da União Européia. Todos consideram que a lei constituiria um avanço em direção à melhoria da qualidade e produtividade no setor, tendo sido ainda mencionado que a prevenção de acidentes faz parte dos princípios éticos da profissão. Contudo, os projetistas apontaram duas possíveis barreiras à implementação de tal lei: a falta de fiscalização acerca do seu real cumprimento, havendo o receio de que as avaliações de risco seriam realizadas apenas com o fim de cumprimento da legislação; a necessidade de mudança de postura dos clientes, que deverão valorizar e aceitar pagar por essa nova atribuição dos projetistas. Esses problemas tendem a ser mais graves no subsetor de edificações residenciais, onde segundo os entrevistados a concorrência predatória entre os projetistas é mais freqüente e a margem de lucro é menor.

\section{Sistematização das sugestões de medidas de segurança nos projetos}

$\mathrm{O}$ check-list elaborado possui quarenta e nove sugestões, sendo apresentado integralmente no anexo A. A distribuição das sugestões entre as disciplinas de projeto foi a seguinte: arquitetônico (45,8\%); estrutural $(33,3 \%)$; instalações $(20,8 \%)$. Vale salientar que várias das medidas propostas têm impacto tanto durante a execução da edificação quanto durante seu uso e manutenção (por exemplo, projetar extremidades de corrimãos acabando em curva, ao invés de ponta; evitar colocar portas ou janelas envidraçadas em frente a lance de escadas). De acordo com o interesse de cada empresa, ou mesmo em novas pesquisas, a lista pode ser ampliada ou customizada para determinado tipo de obra, incluindo ilustrações das práticas apresentadas. Esses aperfeiçoamentos poderiam resultar em um software com um banco de dados das práticas, similar ao desenvolvido por Hinze e Gambatese (1996).

\section{Estudo exploratório}

\section{Procedimentos de integração adotados}

Devido aos prazos exíguos, a demanda pela elaboração de novos projetos e alterações dos já existentes estendeu-se ao longo da execução da obra. Embora o cliente tenha contratado um representante para coordenar o processo de DP, a construtora também alocou um funcionário com a função de gerenciar os seus interesses ao longo desse processo. Semanalmente, durante um período de dois meses, foram realizadas reuniões de compatibilização de projetos na sede da construtora, contando com a participação de representantes do cliente e da construtora, do arquiteto e de projetistas cujas disciplinas estivessem relacionadas à pauta da reunião.

O pesquisador participou de apenas duas dessas reuniões, uma vez que a pauta das mesmas era normalmente muito extensa e outras demandas consideradas prioritárias pelos participantes tornavam difícil a discussão de assuntos de segurança. Contudo, a participação contribuiu para aumentar a compreensão acerca do escopo e detalhes do empreendimento. Tendo em vista efetivar a integração da segurança ao DP, as seguintes ações foram realizadas: 1) análise dos projetos arquitetônico e estrutural sob o ponto de vista da segurança, sendo estes os únicos cujos anteprojetos já existiam no início do processo de DP; 2) elaboração de lista de possíveis demandas de segurança a 
serem consideradas pelos projetistas; 3 ) discussão individual dessas demandas junto a cada projetista; 4) discussão destas demandas nas reuniões semanais de projetistas; 5) avaliação do atendimento às demandas por meio de entrevista com o gerente de produção e visita ao canteiro. Enquanto as etapas 3 e 4 foram realizadas pela coordenadora de projetos da construtora e pelo gerente de produção, as demais foram realizadas pelo pesquisador.

Além disso, com base no plano de longo prazo da obra, foi conduzida uma avaliação de riscos para identificar etapas críticas que receberiam prioridade no planejamento do processo executivo e no processo de projeto. A avaliação foi realizada por um grupo composto pelo pesquisador, pelo gerente de produção e pela coordenadora de projetos. O risco de cada etapa da obra para o sucesso do empreendimento foi avaliado sob quatro critérios: segurança, qualidade, custo e prazo. Em relação à segurança, foi avaliada a severidade e a probabilidade de acidentes em cada grande etapa da construção. Para cada critério, foi atribuído um índice de risco de 1, 2 ou 3, correspondendo, respectivamente, a risco baixo, médio ou alto. Um índice de risco global para cada etapa da obra foi calculado por meio da multiplicação dos índices atribuídos a cada critério.

\section{Resultados da integração}

A Figura 1 ilustra como foram organizadas as demandas de segurança na obra do estudo exploratório. Ainda que apenas o projeto arquitetônico e o estrutural tenham sido analisados, foram identificadas demandas em outras disciplinas, como os projetos de estrutura metálica e telhado, os quais ainda estavam nos estágios iniciais de desenvolvimento. A análise dos riscos dos demais projetos provavelmente indicaria novas demandas não percebidas a partir do estudo do projeto arquitetônico e de prémoldados.

Embora nove demandas tenham sido propostas, nesta seção apenas seis delas são discutidas como exemplos. A demanda 1 (ganchos nas vigas metálicas da estrutura da cobertura) não foi considerada necessária, uma vez que a empresa responsável pelo projeto, fabricação e instalação da estrutura metálica propôs a fixação de cabos-guia e amarração de andaimes na própria estrutura metálica treliçada de suporte ao telhado, ilustrada na Figura 2. Na ocasião da discussão dessa demanda de segurança, a empresa de estrutura metálica ainda apresentou um plano padrão de montagem de suas estruturas no canteiro, o qual foi adaptado para a obra do estudo. A demanda 2 (ganchos nos pilares pré-moldados, que eram peças contínuas com $12 \mathrm{~m}$ de comprimento e esperas de ferro ao

Figura 1: Lista das demandas de segurança a serem discutidas com os projetistas.

\begin{tabular}{|c|c|c|}
\hline DEMANDA & JUSTIFICATIVA & PROJETO(S) \\
\hline $\begin{array}{l}\text { 1. Ganchos nas vigas metálicas da } \\
\text { estrutura da cobertura }\end{array}$ & $\begin{array}{l}\text { Fixar cabos-guia para cinto de segurança e } \\
\text { andaimes, visando construção e manutenção }\end{array}$ & Estrutura metálica \\
\hline $\begin{array}{l}\text { 2. Ganchos nos pilares, do lado externo } \\
\text { da edificação }\end{array}$ & $\begin{array}{l}\text { Fixar cabos-guia para cinto e amarrar } \\
\text { andaimes durante construção e manutenção }\end{array}$ & Pré-moldados \\
\hline $\begin{array}{l}\text { 3. Proteger esperas de ferragens dos } \\
\text { pilares pré-moldados }\end{array}$ & $\begin{array}{l}\text { Evitar impacto contra ou impacto sofrido por } \\
\text { essas ferragens }\end{array}$ & Pré-moldados \\
\hline $\begin{array}{l}\text { 4. Esperas para escada ou escada } \\
\text { permanente incorporada ao prédio } \\
\text { [externamente] }\end{array}$ & $\begin{array}{l}\text { Acesso ao telhado para execução da } \\
\text { cobertura/telhamento e manutenção }\end{array}$ & Arquitetônico \\
\hline $\begin{array}{l}\text { 5. Linhas de cabos-guia sobre o telhado, } \\
\text { junto às platibandas e aos exaustores }\end{array}$ & $\begin{array}{l}\text { Facilidade de montagem das telhas e futuras } \\
\text { manutenções }\end{array}$ & Telhado \\
\hline $\begin{array}{l}\text { 6. Desenvolver mecanismo para trocar } \\
\text { lâmpadas em áreas com pé-direito alto }\end{array}$ & $\begin{array}{l}\text { Viabilizar trocas seguras de lâmpadas em } \\
\text { áreas críticas }\end{array}$ & Elétrico e arquitetônico \\
\hline $\begin{array}{l}\text { 7. Escada incorporada à estrutura para } \\
\text { acesso a janelas altas }(>2,0 \mathrm{~m})\end{array}$ & $\begin{array}{l}\text { Viabilizar acesso seguro a essas janelas em } \\
\text { operações de manutenção }\end{array}$ & Arquitetônico \\
\hline $\begin{array}{l}\text { 8. Checar capacidade de carga das } \\
\text { telhas da cobertura }\end{array}$ & $\begin{array}{l}\text { Garantir circulação segura sobre as telhas } \\
\text { sem que as mesmas sejam danificadas }\end{array}$ & Telhado \\
\hline $\begin{array}{l}\text { 9. Checar meio de união das partes das } \\
\text { vigas metálicas da cobertura }\end{array}$ & $\begin{array}{l}\text { Preferencialmente realizar união com } \\
\text { parafusos e ao nível do solo }\end{array}$ & Estrutura metálica \\
\hline
\end{tabular}


longo de toda sua altura) foi implementada, uma vez que o fabricante normalmente já coloca ganchos para viabilizar o transporte das peças. Entretanto, além disso, decidiu-se deixar furos nos pilares (Figura 2) para a passagem de cabos-guia para a fixação de cintos de segurança, nas cotas de 3,0, 6,0 e 9,0 m.

A demanda 3 (proteger esperas de ferragens dos pilares pré-moldados) também foi implementada, sendo que, por solicitação da construtora, as esperas foram dobradas antes da entrega no canteiro. As demandas 4 e 5 (escada para acesso ao telhado e linhas de cabo-guia sobre o telhado, respectivamente) foram implementadas, embora tenha ocorrido demora para definição do local da escada. A demanda 6 (desenvolver mecanismo para troca de lâmpadas em áreas com pé-direito elevado) não foi implantada, uma vez que não foi encontrada solução mais eficaz do que a usada atualmente pela indústria. No prédio já existente, ao lado da obra, as lâmpadas costumam ser trocadas com auxílio de carrinhos empilhadeiras e guindastes.

No que diz respeito à avaliação do índice de risco, quatro etapas da obra foram consideradas altamente críticas em termos de segurança, principalmente devido aos riscos de queda de altura (estrutura metálica e cobertura) e ao uso de equipamentos de transporte de grande porte (pré-fabricados de concreto e fundações profundas). Os projetos dessas etapas deveriam ser priorizados para revisão do ponto de vista da segurança, o mesmo valendo para o planejamento e controle da segurança dos respectivos processos executivos.

\section{Entrevista com projetista de indústria de outro setor}

O processo de DP da indústria visitada é dividido em três grandes fases: desenvolvimento do conceito; desenvolvimento do produto, processo e qualificação; lançamento do produto e suporte. Em cada fase, há tarefas e ferramentas predeterminadas a serem adotadas (por exemplo, DFA, Análise de Modos e Efeitos de Falha FMEA, análise de tolerâncias). Embora o processo de DP seja mapeado, nem todos os projetos executam todas as tarefas e usam todas as ferramentas. Cabe ao gestor de cada projeto identificar quais tarefas e ferramentas são aplicáveis. Ao final de cada grande fase de projeto há dois procedimentos de revisão que atualizam o projeto e recomendam ou não sua continuidade para a etapa seguinte. O primeiro é denominado QRB (Qualification Review Board), no qual são revisadas decisões técnicas. Uma vez que o projeto seja aprovado no QRB, o mesmo segue para uma nova revisão, chamada passaporte, da qual, além do pessoal técnico, participam representantes da área financeira, logística, marketing, pós-venda e outras de interesse. Tanto o QRB quanto o passaporte são realizados por um grupo, cujos membros são especialistas com conhecimento profundo das tecnologias do projeto, processos necessários e riscos.

Embora a equipe de projeto tente levar em conta diariamente os princípios das técnicas DFx, os mesmos são formalmente colocados em prática em dois momentos do processo de DP - em geral, os X mais enfatizados são os relativos a manufaturabilidade, montagem e manutenção. Na fase de projeto conceitual, essas técnicas são aplicadas para tomar decisões relativas à forma do produto, de modo bastante geral. São produzidos desenhos preliminares do produto e a equipe de trabalho costuma ser dividida em times (por exemplo, o sub-time de sistema de ventilação vai definir o conceito dos venti-

Figura 2: À esquerda: ilustração da estrutura metálica. À direita: furos nos pilares pré-moldados para a passagem de cabos-guia.
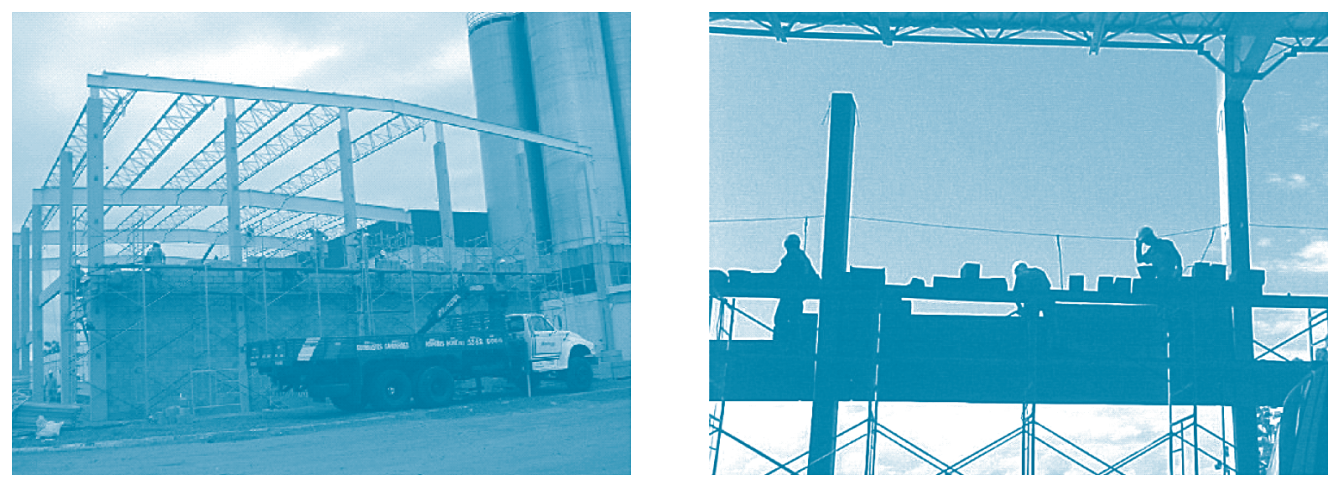
ladores e quantas pás serão utilizadas). Na fase de DP ocorre o DFx tático, baseado em protótipos e desenhos bastante próximos do projeto final, quando são feitos refinamentos no projeto. Nessa fase, novamente as equipes são divididas em subtimes. A integração das interfaces entre os diversos subsistemas constitui um dos principais desafios dos times, visto que as falhas ocorrem normalmente nas interfaces. A análise dos projetos sob o ponto de vista dos princípios DFx é realizada ao longo de uma semana (das $8 \mathrm{~h}$ às $17 \mathrm{~h}$ ) por uma equipe multidisciplinar, que inclui representantes do setor de segurança e meio ambiente (engenheiros e técnicos de segurança) bem como supervisores da linha de montagem, familiarizados com os problemas do chão-de-fábrica. O pessoal do setor de segurança e meio ambiente não permanece em tempo integral em nenhum dos subtimes, circulando entre os mesmos.

O entrevistado salientou que, além do pessoal de segurança, os outros participantes, em especial os supervisores de linha, também são fortes indutores da discussão de assuntos ergonômicos nas sessões DFx. Como exemplo, são identificadas peças pesadas como compressores e submontagens e discutidos mecanismos para reduzir o esforço dos operadores na linha, tais como, nesse caso, a aquisição de um sistema de vácuo para colocar as peças dentro do aparelho. Outro exemplo citado diz respeito à visualização do ponto de aplicação dos parafusos, com o objetivo de evitar que o operador tenha que adotar posturas desconfortáveis para encontrar o ponto correto. Embora a preocupação com questões como essa já ocorra no DFx conceitual, é no DFx tático que as mesmas são de fato resolvidas, com auxílio de protótipos que são montados e desmontados várias vezes. De acordo com o entrevistado, ainda que o uso de desenhos em CAD 3D seja útil, os protótipos apresentam uma contribuição relativa muito maior.

Enquanto as sessões DFx são mais focadas no produto, há outro evento com foco no processo em que também há oportunidade para discutir assuntos ergonômicos, denominado 3P (Pre-Production Planning). Nesse evento, o objetivo é tentar maximizar a produtividade dos operadores, aliada à melhoria das condições de trabalho. São avaliadas questões como as seguintes: como a peça vai chegar até a linha de montagem, como o operador vai ter acesso à peça, quais serão os equipamentos de transporte das peças, quais as distâncias percorridas, quais os movimentos do operador, qual a necessidade de armários e prateleiras para estocagem intermediária das peças. Assim como ocorre com o DFx, o evento 3P consome uma semana inteira e possui uma ênfase bastante prática. A linha de montagem é simulada fisicamente, traçando-se sobre o piso os espaços representativos da linha, equipamentos de transporte e áreas de armazenamento. Os fornecedores dos componentes mais importantes são convocados a participar tanto dos eventos DFx quanto do 3P.

A segurança do usuário final também é uma preocupação no processo de DP, especialmente em função de rigorosas exigências de normas dos mercados dos Estados Unidos e Europa. É comum que representantes dos importadores sejam solicitados a avaliar os produtos do ponto de vista da segurança do usuário ainda na fase de projeto conceitual. $\mathrm{O}$ entrevistado ainda comentou que essas questões também são tratadas em reuniões de FMEA de produto, enfocando perigos como choque elétrico e incêndio do equipamento.

\section{DIRETRIZES PARA INTEGRAC̣ÃO DA SEGURANÇA AO PROCESSO DE DESENVOLVIMENTO DE PRODUTO}

Inicialmente, é necessário definir a responsabilidade principal pela condução da análise de cada projeto do ponto de vista da segurança. Idealmente, essa responsabilidade deve caber ao projetista, visto que o mesmo, mais do que qualquer outro interveniente, possui controle sobre o processo criativo, o nível de amadurecimento das soluções e o ritmo de desenvolvimento do projeto. Contudo, além do pouco conhecimento de muitos projetistas acerca do tema segurança, a falta de valorização desta nova atribuição por parte dos clientes constitui uma barreira a ser superada. O primeiro problema, enquanto não ocorrer disseminação do conhecimento por meio de educação formal, pode ser minimizado por meio da realização da avaliação de riscos juntamente com um gerente de produção com experiência em gestão da segurança ou com um especialista em segurança. Em relação ao segundo problema, uma medida que pode contribuir para sua solução é a inclusão das novas atribuições nos contratos de prestação de serviços dos projetistas. Considerando horizontes de médio e longo prazo, uma medida a ser considerada é a implementação de lei similar à Diretiva Européia 92/57/CEE, que obrigue projetistas e proprietários a participarem formalmente da prevenção dos acidentes de trabalho.

Além dos projetistas, o coordenador do processo de DP, quando existir essa figura como representante do cliente e/ou da construtora, pode prestar contribuição importante à integração da segurança ao DP. O coordenador poderia incluir as demandas de segurança no âmbito de suas tarefas de estabelecimento e cobrança do cumprimento de metas para os projetistas, assim como a distribuição de informações entre os participantes. Por exemplo, uma vez que esteja disponível a aná- 
lise de risco da etapa de anteprojeto de uma determinada disciplina, esta deve ser comunicada a todos os demais projetistas, indicando-se, caso necessário, as implicações daquela análise nos respectivos projetos. O coordenador também deveria agir no sentido de facilitar a compatibilização de detalhes de projeto desenvolvidos devido a demandas de segurança. Por exemplo, o desenvolvimento de meios para troca de lâmpadas em áreas com pé-direito elevado pode impactar tanto o projeto arquitetônico quanto o elétrico, requerendo compatibilização entre ambos. Entretanto, havendo ou não o coordenador de projeto, é essencial o envolvimento do gerente de produção e, preferencialmente, de representantes da equipe de segurança da construtora e/ ou cliente na elaboração das análises de risco. Enquanto o gerente de produção pode fornecer informações essenciais à análise dos projetos do ponto de vista da segurança (por exemplo, tipos de andaimes que serão utilizados), os especialistas em segurança atuam como colaboradores especializados junto aos projetistas.

Com base nos resultados das entrevistas e na experiência do estudo exploratório, ficou claro que as demandas de segurança não devem ser discutidas em detalhes nas reuniões entre todos os projetistas, visto o ambiente normalmente turbulento destas reuniões, com muitos participantes e pauta extensa. Como foi proposto acima, o trabalho inicial de integração deve partir do projetista, com a colaboração de representantes do cliente e/ou construtora alocados para tal finalidade. Em particular, é fundamental que a integração ocorra no projeto de arquitetura, visto que todos os demais projetos possuem forte interface com o mesmo. Além disso, esse projeto determina as especificações básicas de materiais e técnicas construtivas para muitos elementos da edificação que normalmente não possuem um projeto específico, como os pisos e alvenarias.

Propõe-se que a implementação prática da integração siga as etapas do ciclo de gerenciamento de riscos (BAKER et al., 1999): identificação, avaliação, resposta e controle. A identificação de riscos pode ser entendida como forma de captar os requisitos do cliente, nesse caso os trabalhadores de construção e manutenção. As seguintes técnicas e atividades são exemplos de meios para efetivar a identificação de riscos: FMEA; reuniões entre o projetista e o pessoal da produção; uso de check-lists, tais como o proposto neste trabalho; revisões formais de construtibilidade; definição, em linhas gerais, dos principais métodos executivos; visualização em CAD 3D ou 4D (a quarta dimensão é o prazo de execução) da edificação; prototipagem; simulação em escala real da execução de determinados elementos construtivos. $\mathrm{Na}$ prática, a adoção das técnicas e atividades citadas tam- bém contribui para a realização das etapas de avaliação e resposta aos riscos.

A etapa seguinte do ciclo é a avaliação dos riscos, a qual inclui uma estimativa do nível de risco (severidade versus probabilidade) da execução de cada projeto e a compreensão da natureza de cada risco. Entretanto, uma vez que na etapa de projeto normalmente ainda existe grande incerteza quanto aos métodos executivos que serão adotados, tende a ser inviável a compreensão detalhada de cada risco. A mesma incerteza afeta a estimativa de risco, a qual pode ser realizada subjetivamente e vai indicar quais etapas da obra devem ser priorizadas na gestão da segurança.

A resposta aos riscos é a próxima etapa, quando o projetista deve definir quais medidas de projeto serão implementadas para controlar os mesmos. De acordo com Baker et al. (1999), as respostas tipicamente podem envolver a eliminação, a redução, a transferência ou a retenção dos riscos. Em particular, é importante que sejam identificados os principais riscos retidos e que deverão ser gerenciados durante a construção. Nesse sentido, vale enfatizar que não necessariamente as decisões de projeto devem ser modificadas para favorecer a segurança. Por exemplo, uma vez que determinado detalhe arquitetônico seja de difícil execução mas agregue valor do ponto de vista do cliente, será suficiente a identificação dos riscos e o planejamento com grande antecipação de métodos executivos seguros.

Ao final desta etapa, sugere-se a elaboração de um relatório das atividades de gerenciamento de riscos realizadas. Uma proposta de configuração deste relatório é mostrada na Figura 3.

O controle de riscos é a última etapa do ciclo e ocorre durante a execução da obra, visando garantir a implementação das medidas especificadas em projeto. O feedback resultante deste controle, que pode ser realizado por meio da coleta de indicadores de desempenho, contribui para o desenvolvimento de novos projetos mais seguros no futuro. As três primeiras etapas do ciclo de gerenciamento de riscos devem ocorrer em cada fase do projeto (por exemplo, estudo preliminar, anteprojeto e projeto legal), embora seja provável que, após o primeiro ciclo, apenas revisões e ajustes sejam necessários. Vale lembrar que também cabe uma revisão da análise de risco após a elaboração do projeto como construído (as built), principalmente para reavaliar os riscos nas atividades de manutenção da edificação.

A seguir é proposta uma lista de perguntas que pode auxiliar projetistas e colaboradores a desenvolver o ciclo de gerenciamento de riscos: quais os maiores perigos durante a execução deste projeto? Quais medidas podem ser tomadas para eliminar ou reduzir esses perigos ainda 
no projeto? Quais são os principais perigos residuais? Quais as proteções coletivas e individuais que deverão ser utilizadas para controlar aqueles perigos residuais? Como as decisões de projeto podem facilitar a instalação destas proteções coletivas e individuais? Como os materiais e componentes de maior peso e volume necessários à execução deste projeto serão transportados e colocados na posição definitiva? Como é o layout do canteiro e onde esse projeto tem interferência com o layout? Como reduzir a quantidade de serviços em altura e subterrâneos, transferindo atividades para o nível do solo? Quais são as áreas com maior dificuldade de acesso de pessoal para serviços de construção e manutenção? Como a execução deste projeto gera perigos à execução dos outros projetos desta obra?

\section{CONCLUSÕES}

Com base em entrevistas com um grupo de sete projetistas da construção civil, um projetista de indústria de ar-condicionado e um estudo exploratório de integração da segurança ao processo de DP, foram propostas diretrizes para implementação desta integração. Embora as entrevistas tenham indicado que esta é uma prática ainda pouco disseminada na construção civil, é necessário que os projetistas assumam o papel central nessa integração. A adoção de leis que obriguem a consideração formal da segurança nos projetos deve ser considerada seriamente pelos comitês responsáveis por revisões na norma NR-18 (Condições e Meio Ambiente de Trabalho na Indústria da Construção). Em termos operacionais, o uso de técnicas existentes de gerenciamento de riscos, assim como o desenvolvimento de bancos de dados de medidas práticas de integração adequadas à realidade nacional, podem embasar métodos consistentes de integração.

Além disso, na medida em que o processo de DP das edificações passe a ser desenvolvido de modo mais sistematizado, similarmente ao verificado na fábrica de ar- condicionado visitada, a inserção dos assuntos de segurança ao DP tende a ser realizada de modo mais natural, apenas como mais uma dimensão a ser considerada pelas técnicas e procedimentos de DP. A integração também tende a ser mais fácil nas situações em que o projetista é responsável pela execução da obra, tal como ocorria com o projetista de pré-moldados entrevistado neste estudo.

Figura 3: Proposta de formulário para apresentação das análises de risco na etapa de projeto do produto.

\begin{tabular}{|c|c|c|c|}
\hline \multicolumn{4}{|c|}{ ALVENARIAS DE VEDAÇÃO EXTERNAS E INTERNAS } \\
\hline \multicolumn{4}{|c|}{ Materiais: blocos de concreto, cimento, areia, aditivo. } \\
\hline $\begin{array}{l}\text { GRANDES } \\
\text { ETAPAS }\end{array}$ & $\begin{array}{l}\text { PRINCIPAIS } \\
\text { PERIGOS }\end{array}$ & $\begin{array}{l}\text { O PROJETO CONTRIBUI } \\
\text { PARA REDUZIR O RISCO? }\end{array}$ & $\begin{array}{l}\text { GOMO O PROJETO } \\
\text { GONTRIBUI? }\end{array}$ \\
\hline $\begin{array}{l}\text { Descarga e } \\
\text { armazenamento de } \\
\text { materiais no canteiro }\end{array}$ & Queda de materiais & Não & - \\
\hline $\begin{array}{l}\text { Montagem de } \\
\text { andaime fachadeiro ou } \\
\text { simplesmente apoiado }\end{array}$ & $\begin{array}{l}\text { Queda de materiais e } \\
\text { pessoas desde os } \\
\text { andaimes }\end{array}$ & Sim & $\begin{array}{l}\text { Colocação de furos ou } \\
\text { esperas nos pilares para } \\
\text { passagem de cabos-guia } \\
\text { ou amarrar os andaimes }\end{array}$ \\
\hline \multirow{4}{*}{ Levantamento da alvenaria } & Queda de materiais & Não & - \\
\hline & Queda de pessoas & Sim & $\begin{array}{l}\text { Colocação de furos ou } \\
\text { esperas nos pilares, para } \\
\text { passagem de cabos-guia }\end{array}$ \\
\hline & $\begin{array}{l}\text { Contato de cimento } \\
\text { com a pele }\end{array}$ & Não & - \\
\hline & $\begin{array}{l}\text { Desabamento de } \\
\text { paredes }\end{array}$ & Sim & $\begin{array}{l}\text { Previsão de ancoragens } \\
\text { adequadas }\end{array}$ \\
\hline \multicolumn{4}{|c|}{ Áreas críticas: paredes $\mathrm{P} 1, \mathrm{P} 2$ e P4, com perímetro circular e altura de 4,0 m. } \\
\hline Instalações previstas para & lanutenção: & & \\
\hline
\end{tabular}


Dentre as necessidades de pesquisas futuras, cabe a proposição e validação de métodos de integração, a ampliação do check-list de medidas de integração proposto neste trabalho, o desenvolvimento de ferramentas para disseminar o conhecimento sobre segurança entre os projetistas (por exemplo, softwares ou manuais), assim como um levantamento mais abrangente das percepções dos mesmos quanto ao assunto.

\section{Artigo recebido em 19/10/2004 Aprovado para publicação em 25/02/2005}

\section{- Referências Bibliográficas}

BAKER, S.; PONNIAH, D.; SMITH, S. Risk response techniques employed currently for major projects. Construction Management and Economics, v. 17, n. 2, p. 205-213, 1999.

BOOTHROYD, G.; DEWHURST, P. Design for assembly. Amherst, Mass: Department of Mechanical Engineering, University of Massachusetts, 1983.

BUDNICK, P.; BLOSWICK, D.; BROWN, D. Ergonomics and concurrent design. In: BHATTACHARYA, A.; MCGLOTHLIN, J. (Eds.) Occupational ergonomics: theory and applications. New York: Marcel Dekker, p. 719-731, 1996.

CHURCHER, D.; STARR, G Incorporating construction health and safety into the design process. In: DUFF, R.; JASELSIKS, E.; SMITH, G. (Eds). Safety and health on construction sites. Gainesville: CIB Publication 209 , W99, p. 31-41, 1997.
COBLE, R.; BLATTER, R. Concerns with safety in design/build process. Journal of Architectural Engineering, v. 5, n. 2, p. 44-48. June, 1999.

FUNDAÇÃO EUROPÉIA PARA A MELHORIA DAS CONDICOÕES DE VIDA E DO TRABALHO. Do projeto ao estaleiro: condições de trabalho, qualidade e resultados econômicos. Dublim: Fundação Européia para a Melhoria das Condições de Vida e do Trabalho, 1989.

HELANDER, M.; WILLEN, B. Design for human assembly. In: KARWOSWSKI, W.; MARRAS, W. (Eds.) The occupational ergonomics handbook. Boca Raton: CRC Press, p. 1.631 1.640, 1999.

HELANDER, M.; FURTADO, D. Product design for manual assembly. In: HELANDER, M.; NAGAMACHI, M. (Eds.). Design for Manufacturability: a systems approach to concurrent engineering and ergonomics. London: Taylor and Francis, p. 171$188,1992$.
HINZE, J.; GAMBATESE, J. Addressing construction worker safety in project design. Austin: The Construction Industry Institute, 149, p. 1996.

HISLOP, R. Construction site safety: a guide for managing contractors. Boca Raton: Lewis Publishers, 244 p., 1999.

LAKKA, A.; SAUNI, S. Construction safety coordination in Finland. In: DIAS, L.A; COBLE, R. Construction Safety Coordination in the European Union. Milano: CIB Publication 238

- W99 Safety and Health on Construction Sites, p. 55-63, 1999.

MACCOLLUM, D. Construction safety planning. New York: Van Nostrand Reinhold, 285 p., 1995.
MACKENEZIE, J.; GIBB, A.; BOUCHLAGHEM, M. Communication: the key to designing safely. In: INTERNATIONAL CONGRESS ON DESIGNING FOR SAFETY, 1. 2000 , London. Proceedings... Loughborough: Loughborough University, 2000. Disponível em $<$ www.eci-online.org $>$. Acesso em: 20 ago. 2000

PRUGH, P. A conversation on the ethics of public safety in design. In DUFF, R.; JASELSKIS, E.; HINZE, J. (Eds.) Safety and Health on Construction Sites. Gainesville: CIB Publication 187, W99, p. 233-237, 1996.

SINNOTT, R. Safety and security in building design. New York: Van Nostrand Reinhold Company, 1985

- Agradecimentos

$\mathrm{O}$ autor agradece ao CNPq e à FAPERGS pelo apoio concedido à realização desta pesquisa.

- Sobre os autores

Tarcisio Abreu Saurin, Dr.

Universidade Federal do Rio Grande do Sul (UFRGS), Programa de Pós-Graduação em Engenharia de Produção (PPGEP),

Laboratório de Otimização de Produtos e Processos (LOPP)

Professor colaborador e pesquisador do PPGEP/UFRGS

Endereço: Praça Argentina, n. 9, $2^{\circ}$ andar, sala LOPP. CEP 90040-020. Porto Alegre (RS)

Telefone: 51-3316-3490

Fax: 51-3316-4007

E-mail: tasaurin@terra.com.br 
Anexo A: check-list de medidas de segurança na etapa de projeto.

\begin{tabular}{|c|c|c|}
\hline MEDIDA & PROJETO & JUSTIFICATIVA \\
\hline $\begin{array}{l}\text { Projetar extremidades de corrimãos } \\
\text { acabando em curva, ao invés de ponta }\end{array}$ & Arquitetônico & $\begin{array}{l}\text { Evitar enganchamentos de roupas e } \\
\text { minimizar efeitos de impactos contra o } \\
\text { corrimão }\end{array}$ \\
\hline $\begin{array}{l}\text { Evitar colocar portas ou janelas envidraçadas } \\
\text { em frente a lance de escadas }\end{array}$ & Arquitetônico & $\begin{array}{l}\text { Minimizar efeitos de impactos contra } \\
\text { portas ou janelas }\end{array}$ \\
\hline $\begin{array}{l}\text { Prever esperas para escada de mão ou } \\
\text { incorporar escada permanente para acesso a } \\
\text { telhados, visando manutenção. Para impedir o } \\
\text { uso da escada por pessoal não autorizado, } \\
\text { sua parte inferior pode ser destacável ou } \\
\text { cercada e com fechadura }\end{array}$ & Arquitetônico & Evitar improvisos no acesso a telhados \\
\hline $\begin{array}{l}\text { Prever alçapões de acesso a telhados com } \\
\text { dimensões que permitam a passagem de uma } \\
\text { pessoa (no mínimo } 60 \mathrm{~cm} \text { x } 60 \mathrm{~cm} \text { ) }\end{array}$ & Arquitetônico & Viabilizar acesso embaixo de telhados \\
\hline $\begin{array}{l}\text { Localizar alçapões de acesso distantes da } \\
\text { periferia da estrutura }\end{array}$ & Arquitetônico & Viabilizar acesso embaixo de telhados \\
\hline $\begin{array}{l}\text { Todas as platibandas, sacadas, parapeitos de } \\
\text { janelas e outros locais similares com perigo } \\
\text { de queda devem possuir a altura mínima de } \\
\text { guarda-corpos exigida pela NR-18 }(1,20 \mathrm{~m})\end{array}$ & Arquitetônico & $\begin{array}{l}\text { Evitar a colocação de proteção } \\
\text { complementar para prevenção de quedas }\end{array}$ \\
\hline $\begin{array}{l}\text { Especificar telhas com capacidade de carga } \\
\text { para suportar uma pessoa caminhando sobre } \\
\text { a mesma, ou projetar passarela para } \\
\text { circulação sobre as telhas }\end{array}$ & Arquitetônico & $\begin{array}{l}\text { Evitar colapso das telhas em caso de } \\
\text { circulação sobre as mesmas }\end{array}$ \\
\hline Minimizar a inclinação dos telhados & Arquitetônico & $\begin{array}{l}\text { Reduzir probabilidade de escorregamento de } \\
\text { pessoas e materiais }\end{array}$ \\
\hline $\begin{array}{l}\text { Não projetar rampas que mudem de } \\
\text { inclinação repentinamente sem aviso. } \\
\text { É aconselhável a colocação de um } \\
\text { guarda-corpo acompanhando a } \\
\text { inclinação da rampa }\end{array}$ & Arquitetônico & Evitar quedas e tropeções \\
\hline $\begin{array}{l}\text { Projetar rotas de pedestres de modo } \\
\text { que se situem um pouco afastadas da } \\
\text { fachada }\end{array}$ & Arquitetônico & $\begin{array}{l}\text { Evitar que pessoas batam a cabeça em } \\
\text { janelas ou portas abertas }\end{array}$ \\
\hline $\begin{array}{l}\text { Evitar saídas de estacionamento cegas, onde } \\
\text { motorista do veículo e pedestre não } \\
\text { visualizam um ao outro }\end{array}$ & Arquitetônico & Evitar atropelamentos \\
\hline $\begin{array}{l}\text { Projetar meios para que janelas em andares } \\
\text { altos possam ser limpas por dentro da } \\
\text { edificação. Por exemplo, especificar janelas } \\
\text { tipo maximar que permitam giro de } 90^{\circ} \text { ou } \\
\text { janelas que possam ser retiradas para } \\
\text { limpeza }\end{array}$ & Arquitetônico & Prevenir quedas de altura \\
\hline
\end{tabular}




\begin{tabular}{|c|c|c|}
\hline MEDIDA & PROJETO & JUSTIFIGATIVA \\
\hline $\begin{array}{l}\text { Em caso de haver passarelas ou saliências } \\
\text { junto à fachada, prever cabo-guia para fixar } \\
\text { cinto de segurança }\end{array}$ & Arquitetônico & $\begin{array}{l}\text { Facilitar uso de cinto de segurança caso a } \\
\text { passarela ou saliência seja usada para } \\
\text { acesso em serviços de manutenção }\end{array}$ \\
\hline $\begin{array}{l}\text { Prever meios para limpeza interna de } \\
\text { telhados envidraçados. Por exemplo, em } \\
\text { coberturas zenitais, planejar plataformas } \\
\text { móveis, internas ao prédio, para facilitar } \\
\text { atividades de manutenção }\end{array}$ & Arquitetônico & $\begin{array}{l}\text { Viabilizar manutenção segura da parte } \\
\text { interna de telhados envidraçados }\end{array}$ \\
\hline $\begin{array}{l}\text { Projetar meios para limpeza e manutenção } \\
\text { externa de telhados. Por exemplo, prever } \\
\text { linhas de cabo-guia (transversais e } \\
\text { longitudinais) para circulação sobre telhado }\end{array}$ & Arquitetônico & Facilitar circulação segura sobre o telhado \\
\hline $\begin{array}{l}\text { Evitar especificação de revestimentos } \\
\text { cerâmicos externos nas platibandas }\end{array}$ & Arquitetônico & $\begin{array}{l}\text { Dificuldades de acesso à platibanda para } \\
\text { instalação das peças cerâmicas }\end{array}$ \\
\hline $\begin{array}{l}\text { Evitar degraus e depressões próximos a } \\
\text { janelas e aberturas no piso }\end{array}$ & Arquitetônico & Evitar quedas de altura \\
\hline $\begin{array}{l}\text { Evitar projeto de volumes de fachada com } \\
\text { largura menor que } 1,0 \mathrm{~m}\end{array}$ & Arquitetônico & $\begin{array}{l}\text { Dificuldade de instalação de andaimes } \\
\text { suspensos para serviços de revestimento, } \\
\text { levando a improvisos }\end{array}$ \\
\hline $\begin{array}{l}\text { Projetar pisos ao redor de equipamentos } \\
\text { mecânicos com um único nível }\end{array}$ & Arquitetônico & $\begin{array}{l}\text { Evitar tropeções e impacto contra os } \\
\text { equipamentos }\end{array}$ \\
\hline $\begin{array}{l}\text { Projetar meios para troca de lâmpadas em } \\
\text { áreas com pé-direito elevado }(>3,5 \mathrm{~m})\end{array}$ & Arquitetônico & Prevenir quedas de altura \\
\hline $\begin{array}{l}\text { Projetar floreiras que possuam acesso direto } \\
\text { a partir de janela logo em frente, ou projetar } \\
\text { escada externa de acesso às floreiras }\end{array}$ & Arquitetônico & $\begin{array}{l}\text { Prevenir quedas de altura no acesso à } \\
\text { floreira }\end{array}$ \\
\hline $\begin{array}{l}\text { Locar escadas e rampas de modo que se } \\
\text { situem paralelas e adjacentes ao edifício, ao } \\
\text { invés de perpendicularmente à estrutura }\end{array}$ & Arquitetônico & $\begin{array}{l}\text { Evitar a criação de passarelas onde possa } \\
\text { haver perigo de queda de materiais sobre } \\
\text { pedestres passando abaixo }\end{array}$ \\
\hline $\begin{array}{l}\text { Prever furos em pilares nas cotas de } 0,7 \mathrm{~m} \text { e } \\
1,20 \mathrm{~m} \text { acima do nível do piso }\end{array}$ & Estrutural & $\begin{array}{l}\text { Facilitar instalação de guarda-corpos e } \\
\text { cabos-guia para fixar cinto de segurança }\end{array}$ \\
\hline Prever ganchos em pilares, vigas e lajes & Estrutural & $\begin{array}{l}\text { Facilitar amarração de andaimes fachadeiros } \\
\text { e cabos-guia para cinto de segurança }\end{array}$ \\
\hline $\begin{array}{l}\text { Prever ganchos nas vigas de periferia, em } \\
\text { edificações com cinco ou mais pavimentos }\end{array}$ & Estrutural & $\begin{array}{l}\text { Facilitar instalação das plataformas de } \\
\text { proteção, obrigatórias pela NR-18 }\end{array}$ \\
\hline $\begin{array}{l}\text { Projetar estruturas metálicas que possam } \\
\text { ser unidas com parafuso ao invés de solda }\end{array}$ & Estrutural & $\begin{array}{l}\text { Facilitar execução das uniões entre as } \\
\text { peças da estrutura }\end{array}$ \\
\hline $\begin{array}{l}\text { Projetar platibandas em concreto armado } \\
\text { capazes de suportar carga de andaimes } \\
\text { suspensos }\end{array}$ & Estrutural & $\begin{array}{l}\text { Viabilizar instalação de andaimes fixados nas } \\
\text { platibandas, eliminando assim interferências } \\
\text { entre as vigas de sustentação dos andaimes } \\
\text { e a impermeabilização da laje de cobertura }\end{array}$ \\
\hline $\begin{array}{l}\text { Projetar ganchos na laje de cobertura, } \\
\text { para fixação das vigas de sustentação de } \\
\text { andaimes suspensos }\end{array}$ & Estrutural & $\begin{array}{l}\text { Facilitar instalação dos andaimes de acordo } \\
\text { com a NR-18 }\end{array}$ \\
\hline
\end{tabular}




\begin{tabular}{|c|c|c|}
\hline MEDIDA & PROJETO & JUSTIFICATIVA \\
\hline $\begin{array}{l}\text { Projetar bloco de fundação da grua em local } \\
\text { que possa ser aproveitado na estrutura } \\
\text { definitiva da edificação ou em local que não } \\
\text { atrapalhe, podendo ser mantido em definitivo }\end{array}$ & Estrutural & $\begin{array}{l}\text { Evitar demolição do bloco de fundação da } \\
\text { grua e aproveitá-lo na estrutura definitiva }\end{array}$ \\
\hline $\begin{array}{l}\text { Projetar estruturas pré-fabricadas em que } \\
\text { as vigas possam ser colocadas sobre os } \\
\text { pilares ao invés de entre eles }\end{array}$ & Estrutural & $\begin{array}{l}\text { Reduzir probabilidade de colapso das } \\
\text { estruturas durante a colocação }\end{array}$ \\
\hline $\begin{array}{l}\text { Projetar peças pré-fabricadas de um único } \\
\text { tamanho ou forma, ou que sejam de } \\
\text { tamanhos de fácil diferenciação }\end{array}$ & Estrutural & $\begin{array}{l}\text { Reduzir probabilidade de confusão na } \\
\text { escolha das peças }\end{array}$ \\
\hline $\begin{array}{l}\text { Especificar prolongamento da armadura das } \\
\text { vigas e lajes vizinhas ao poço do elevador }\end{array}$ & Estrutural & $\begin{array}{l}\text { O prolongamento da armadura vai servir } \\
\text { como proteção contra queda de materiais }\end{array}$ \\
\hline $\begin{array}{l}\text { Projetar aberturas na laje e/ou paredes do } \\
\text { subsolo para descarregar materiais } \\
\text { diretamente pelas mesmas }\end{array}$ & Estrutural & $\begin{array}{l}\text { Viabilizar opção de layout do canteiro com } \\
\text { materiais estocados no subsolo }\end{array}$ \\
\hline Adotar painéis coloridos para fôrmas de lajes & Estrutural & $\begin{array}{l}\text { Tornar mais visíveis obstáculos sobre a laje } \\
\text { e evitar tropeções }\end{array}$ \\
\hline $\begin{array}{l}\text { Especificar altura limite para lançamento de } \\
\text { concreto nas fôrmas }\end{array}$ & Estrutural & $\begin{array}{l}\text { Minimizar carga nas fôrmas e perigo de } \\
\text { colapso das mesmas durante a } \\
\text { concretagem }\end{array}$ \\
\hline $\begin{array}{l}\text { Especificar os locais onde são necessários } \\
\text { escoramentos das estruturas vizinhas ou } \\
\text { existentes no canteiro de obras }\end{array}$ & Estrutural & $\begin{array}{l}\text { Evitar desmoronamentos e colapso de } \\
\text { estruturas vizinhas ou existentes }\end{array}$ \\
\hline $\begin{array}{l}\text { Projetar elementos estruturais que possam } \\
\text { ser pré-montados no nível do solo }\end{array}$ & Estrutural & Minimizar trabalho em altura \\
\hline $\begin{array}{l}\text { Especificar barras de fechamento de pilares } \\
\text { em altura superior à cabeça dos } \\
\text { trabalhadores }(>1,80 \mathrm{~m})\end{array}$ & Estrutural & $\begin{array}{l}\text { Evitar impacto contra as barras de } \\
\text { fechamento de pilares }\end{array}$ \\
\hline $\begin{array}{l}\text { Identificar estruturas que receberão cargas } \\
\text { significantes durante a construção }\end{array}$ & Estrutural & $\begin{array}{l}\text { Consideração de cargas acidentais no } \\
\text { projeto estrutural }\end{array}$ \\
\hline $\begin{array}{l}\text { Especificar em planta a localização de } \\
\text { tubulações subterrâneas pré-existentes no } \\
\text { terreno }\end{array}$ & Instalações & $\begin{array}{l}\text { Evitar perfuração acidental das tubulações } \\
\text { pré-existentes }\end{array}$ \\
\hline $\begin{array}{l}\text { Projetar sistemas de iluminação definitivos } \\
\text { que possam ser erguidos conjuntamente com } \\
\text { os elementos estruturais }\end{array}$ & Instalações & Minimizar trabalho em altura \\
\hline $\begin{array}{l}\text { Projetar tubulações que conduzam } \\
\text { líquidos em nível inferior às tubulações } \\
\text { elétricas }\end{array}$ & Instalações & $\begin{array}{l}\text { Evitar curto-circuito em caso de } \\
\text { vazamentos }\end{array}$ \\
\hline $\begin{array}{l}\text { Evitar a passagem de cabos de alta tensão } \\
\text { pelas áreas de trabalho }\end{array}$ & Instalações & Evitar impacto contra cabos de alta tensão \\
\hline $\begin{array}{l}\text { Posicionar controles mecânicos, } \\
\text { hidráulicos e elétricos em áreas de fácil } \\
\text { visualização e acesso }\end{array}$ & Instalações & $\begin{array}{l}\text { Facilitar acionamento de controles em } \\
\text { situações de emergência }\end{array}$ \\
\hline
\end{tabular}




\begin{tabular}{|l|l|l|}
\hline \multicolumn{1}{|c|}{ MEDIDA } & PROJETO & \multicolumn{1}{c|}{ JUSTIFICATIVA } \\
\hline $\begin{array}{l}\text { Projetar válvulas com extensores ou com } \\
\text { acionamento remoto, quando localizadas } \\
\text { próximas a materiais perigosos ou espaços } \\
\text { confinados }\end{array}$ & Instalações \\
\hline $\begin{array}{l}\text { Assegurar que válvulas de alívio } \\
\text { descarreguem longe de áreas de trabalho e } \\
\text { vias de circulação }\end{array}$ & Instalações \\
\hline $\begin{array}{l}\text { Projetar todos equipamentos mecânicos e de } \\
\text { ar-condicionado para suportar as exigências } \\
\text { de corrosão e cargas acidentais durante a } \\
\text { construção }\end{array}$ & Instalações & $\begin{array}{l}\text { Evitar paralisação de trabalhos e bloqueio de } \\
\text { vias de circulação }\end{array}$ \\
\hline $\begin{array}{l}\text { Especificar as cores de todas as tubulações } \\
\text { de acordo com a NR-26 }\end{array}$ & Instalações \\
\hline $\begin{array}{l}\text { Identificar nas plantas, ou se possível na } \\
\text { própria tubulação, o sentido do fluxo }\end{array}$ & $\begin{array}{l}\text { Fociapso ou falhas operacionais destes } \\
\text { trabalhadores }\end{array}$ \\
\hline
\end{tabular}

